\title{
(6) OPEN ACCESS \\ Fathers' intelligence measured at age $18-20$ years is associated with offspring smoking: linking the Swedish 1969 conscription cohort to the Swedish Survey of Living Conditions
}

\author{
Alma Sörberg Wallin, ${ }^{1}$ Andreas Lundin, ${ }^{1}$ Bo Melin, ${ }^{2}$ Tomas Hemmingsson ${ }^{1,3}$
}

${ }^{1}$ Unit of Occupational Medicine, Institute of Environmental Medicine Karolinska Institutet, Stockholm, Sweden ${ }^{2}$ Division of Psychology, Department of Clinical Neurosciences, Karolinska Institutet, Stockholm, Sweden ${ }^{3}$ Centre for Social Research on Alcohol and Drugs, Stockholm University, Stockholm, Sweden

\section{Correspondence to}

Alma Sörberg Wallin, Unit of Occupational Medicine Institute of Environmental Medicine, Karolinska Institute, Solnavägen 4 ,

Stockholm 113 65, Sweden alma.sorberg.wallin@ki.se

Received 4 June 2015 Revised 8 October 2015 Accepted 9 October 2015 Published Online First 29 October 2015

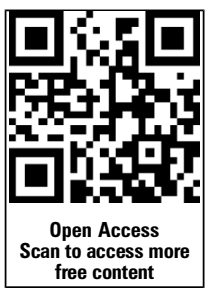

CrossMark

To cite: Sörberg Wallin $A$, Lundin A, Melin B, et al. $J$ Epidemiol Community Health 2016:70:396-401.

\begin{abstract}
Background An association between lower IQ of parents, measured early in life, and smoking among their offspring has been reported. The extent to which other background factors account for this association is unknown.
\end{abstract}

Methods Data on IQ, smoking, mental health, social class, parental divorce and social problems in a cohort of men born during 1949-1951 and conscripted for military service in 1969 were linked to smoking data on 682 offspring interviewed in the Swedish Surveys of Living Conditions 1984-2009.

Results In an age-adjusted model, a one-step decrease on a stanine scale was associated with an OR of 1.19 (95\% Cl 1.04 to 1.35 ) for offspring smoking. Adjusting for father's socioeconomic background and smoking, mental illness and social problems in youth only marginally lowered the OR's.

Conclusions Lower IQ among fathers measured at ages 18-20 years was associated with smoking in their offspring. The association was not explained by father's social class in childhood or a higher prevalence of mental illness, social problems or smoking measured among the fathers in their late adolescence.

\section{INTRODUCTION}

Smoking is one of the highest-ranked contributors to the global burden of disease and mortality. ${ }^{1}$ It typically starts in adolescence and often continues into adulthood. ${ }^{2}$ Previous research has found inverse associations of general intelligence, measured in youth, with smoking and other adverse health behaviours, ${ }^{4-6}$ and also with morbidity and mortality across the life course. ${ }^{3} 67$ The associations are typically not explained by socioeconomic and social conditions during the upbringing, but education and socioeconomic conditions in adulthood seem to be more important..$^{3-5} 7$ It has also been suggested that lower intelligence may result in poorer understanding of health consequences and thereby, increases the risk of smoking. ${ }^{6}$

Parental characteristics can directly or indirectly affect many of the circumstances associated with children's smoking later in life. Several studies have reported that social and psychosocial conditions in the parental home are associated with smoking among children. ${ }^{8-10}$ For example, adverse childhood experiences, such as parental divorce ${ }^{11} 12$ or having a mentally-ill household member, ${ }^{11}$ have been related to an increased risk of smoking in adulthood. Parenting style and parents' attitudes can also have an influence on smoking behaviour in adolescent and adult offspring. ${ }^{13-15}$ In an even longer perspective, results from an Australian study ${ }^{16}$ indicate that smoking behaviour can have intergenerational implications. In this study, an association was found between the occupational status of grandparents before the birth of a grandchild and the prevalence of smoking among grandchildren at age 14 years. The association remained unaffected by adjustments for income in the grandchild's' family. ${ }^{16}$

Parental intelligence has also been found to be associated with smoking in their offspring. Hart et $a l^{17}$ found that, in a cohort of 179 Scottish men and women and their offspring, childhood IQ of the parents was associated with the amount of smoking among their offspring. The association remained unaffected by adjustment for parental social class and category of deprivation, but there was no control for other parental characteristics. In a larger British cohort, including 2202 parents and their offspring, an association of parental IQ with emotional and attention problems in their children at the age of about 7 years was partly accounted for by cognitive and emotional support from parents and maternal psychological distress. ${ }^{18}$ It is also possible that parental characteristics mediate the association between parental IQ and offspring smoking. Since socioeconomic circumstances in grandparents have been found to predict smoking in grandchildren, it is also possible that socioeconomic and social factors in the grandparental generation act as confounders in the association. Further, there is a lack of large studies of associations between parental intelligence and offspring health behaviours in adolescence and adulthood, when the offspring make their own independent health decisions.

For the present investigation, we took advantage of the availability of data on IQ, and social and psychosocial factors at age 18-20 years among men in the Swedish 1969 conscription cohort, born 19491951 , and on the smoking behaviour of a subset of 749 of their offspring, born 1968-1993, who were randomly sampled and interviewed in the Swedish Surveys of Living Conditions during the years 1984-2009. Using these data, we investigated whether fathers' IQ, measured in late adolescence, is associated with smoking among their children, and the extent to which any association is explained by other social and psychosocial factors among the fathers. 


\section{METHODS}

\section{Study population}

The study was based on data from a nation-wide survey of 49321 young Swedish males of ages 18-20 years, who were conscripted for compulsory military service in 1969 and 1970, and subsequently followed as a cohort by linkage to national registers and other data. The background of the Swedish conscription surveys and the variables included have been presented in detail elsewhere. ${ }^{19}{ }^{20}$ Only 2-3\% of all Swedish men were exempted from conscription at this time; in most cases, due to severe handicaps or congenital disorders. Ninety-eight per cent of all men conscripted in 1969 and 1970 were born in 19491951, while the remaining $2 \%$ were born before 1949 . Of these men, 39095 had a total of 91018 children born during 19682004. The Swedish Surveys of Living Conditions have been conducted by Statistics Sweden annually since 1975, using a national random sample of the population aged 16-84 years. Samples varying from 7000 to 10000 persons have been interviewed every year, each in a $1 \mathrm{~h}$ private session, and the response rates have been around $80 \%$ or more. Of the 91018 children, 72728 were in at least one of the sample frames of the Swedish Surveys of Living Conditions 1984-2009, that is, were 16 years or older at the time of sampling. Among the children, 749 were sampled and subsequently interviewed (10\% of the 72728 individuals). This subset of children (linked by unique individual identifiers to information on fathers, mothers and grandfather through the Multigenerational Register at Statistics Sweden) makes up the study population in the present investigation.

\section{Information on IQ and other variables concerning the fathers in the conscription survey of 1969}

The IQ tests, which have been described elsewhere, ${ }^{21} 22$ included subtests of logic/general intelligence; verbal test of synonym detection; of visuospatial/geometric perception; and of technical/mechanical skills with mathematical/physics problems. Correlations between the subtests ranged from 0.50 to 0.75 . The outcome of each subtest was ranked 1-9 according to a standard-nine scale, and then transformed into a new stanine scale $($ mean $=5, \mathrm{SD}=2)$ as a measure of general ability. This measure was used to estimate the conscript's ability to profit from education and finding the right level of learning demands in military training, and corresponds to approximate IQ bands of: <74, 74-81, 82-89, 90-95, 96-104, 105-110, 111-118, $119-126,>126^{21}$

The conscripts were also asked to complete questionnaires concerning social background, behaviour and social adjustment, and substance use, for example, cigarette smoking, and drug and alcohol consumption. Cigarette smoking was classified into one of three levels (non-smokers, 1-10 cigarettes/day, $>10$ cigarettes/day). Only current smoking was included in the questionnaire. A composite variable, 'risky use of alcohol', was created from affirmative answers to one or more of the following questions: consumption of $>250 \mathrm{~g} 100 \%$ alcohol/week, ever drinking alcohol as an 'eye-opener' during a hangover, ever having been apprehended for drunkenness, or having 'often' been drunk (other choices were 'rather often', 'sometimes', and 'never'). This variable has been found to predict alcohol-related disorders and disability pension in adulthood. ${ }^{23} 24$ Questionnaire information was also obtained on parental divorce and whether the conscript had ever been in contact with police or child welfare authorities (at least once), and was used as indicators of conflicts among family members and social or behavioural problems, respectively. These variables have, in various degrees, been associated with negative outcomes later in life in this cohort ${ }^{19}{ }^{22^{25-29}}$ and might be indicators of adverse circumstances in the offsprings' home environment.

All conscripts also went through a medical examination and were interviewed by a psychologist. Those reporting or presenting psychiatric symptoms or disorders were referred to a psychiatrist, and any mental disorder was diagnosed according to the Swedish version of the 8th Revision of the International Classification of Diseases (ICD-8). About $12 \%$ of the conscripts were given a psychiatric diagnosis. ${ }^{30}$

Socioeconomic position in the conscripts' childhood was taken from occupation of conscript's parents as registered in the Swedish National Population and Housing Census 1960, and classified into four groups: unskilled manual workers, skilled manual workers, non-manual workers and farmers, and those not possible to classify. Education levels of the conscripts and the mothers of offspring were taken from the Swedish National Population and Housing Census 1990, and classified as less or more than 12 years of education (upper secondary).

\section{Follow-up data on smoking}

The 749 children were interviewed in at least one annual Survey of Living Conditions, randomly distributed between 1984 and 2009 and depending solely on the chance occurrence of their inclusion in a particular annual Survey of Living Conditions sample. In these surveys, respondents were asked if they were currently smokers or non-smokers. No information on the number of cigarettes smoked was available in these surveys.

\section{Data analysis}

The representativeness of the sample of offspring 16 years or older ( $\mathrm{n}=682$ with information on all variables) was evaluated by comparing the prevalence of covariates with those of the total conscript cohort with offspring 16 years or older in 2009 $(\mathrm{N}=38$ 564).

The association between paternal IQ and offspring smoking was assessed using logistic regression models to estimate ORs with 95\% CIs in multivariate models. Paternal IQ was modelled as a continuous variable, with OR's given for each one-step decrease on the stanine scale. Additional analyses were also performed in which paternal IQ was classified into three groups where low IQ corresponds to scoring 1-3; middle IQ refers to scoring 4-6 and high IQ refers to scoring 7-9 on the stanine scale. This corresponds approximately to score $<90,90-110$ and $>110$ on the traditional IQ scale. ${ }^{21}$ An interaction analysis was performed to test for interaction with offspring sex. The logistic regression analyses are based on those 682 participants in the subset with complete data on all included variables. All analyses were adjusted for age and year of interview.

\section{RESULTS}

Comparison of covariates with regard to their prevalence between the subsample (offspring interviewed in the Surveys of Living Conditions 1984-2009) and the full cohort (conscripts' offspring aged 16 years and older during 1984-2009), showed good agreement (table 1). This would be expected if the sampling for the Surveys of Living Conditions was truly random, and if there was no important refusal bias.

Table 2 shows characteristics of the offspring in the sample. Among the 682 offspring included in the analyses, 70 reported being smokers: 46 female and 24 male.

Table 3 shows the associations of fathers' characteristics and mothers' educational level with their offspring's smoking. 
Table 1 Prevalence (\%) of risk factors in the full sample and in the sub-cohort with offspring who participated in the Swedish Surveys of Living Conditions 1984-2009

\begin{tabular}{|c|c|c|}
\hline Prevalence of conditions & $\mathbf{N}$ & Per cent \\
\hline \multicolumn{3}{|l|}{ IQ (mean) } \\
\hline Full cohort* & 38502 & 4.54 \\
\hline Samplet & 682 & 4.57 \\
\hline \multicolumn{3}{|c|}{ Contact with police and childcare authorities } \\
\hline Full cohort* & 37946 & 29.44 \\
\hline Sample† & 682 & 26.54 \\
\hline \multicolumn{3}{|l|}{ Psychiatric diagnoses } \\
\hline Full cohort* & 38564 & 10.93 \\
\hline Samplet & 682 & 8.80 \\
\hline \multicolumn{3}{|l|}{ Smoking $>10$ cigarettes/day } \\
\hline Full cohort* & 37980 & 27.63 \\
\hline Samplet & 682 & 26.69 \\
\hline \multicolumn{3}{|l|}{ Risky use of alcohol } \\
\hline Full cohort* & 37028 & 13.39 \\
\hline Samplet & 682 & 9.97 \\
\hline \multicolumn{3}{|l|}{ Parental divorce } \\
\hline Full cohort* & 37847 & 10.50 \\
\hline Samplet & 682 & 9.29 \\
\hline \multicolumn{3}{|c|}{ (Grand-) father unskilled worker in 1960} \\
\hline Full cohort* & 38564 & 33.17 \\
\hline Sample† & 682 & 31.09 \\
\hline \multicolumn{3}{|l|}{ Education $\leq 12$ years $\ddagger$} \\
\hline Full cohort* & 37822 & 71.83 \\
\hline Samplet & 682 & 71.85 \\
\hline \multicolumn{3}{|c|}{ Education of mother of child, $\leq 12$ years } \\
\hline Full cohort* & 38001 & 70.33 \\
\hline Samplet & 682 & 70.67 \\
\hline \multicolumn{3}{|l|}{ Child birth year (median) } \\
\hline Full cohort* & 38564 & 1980 \\
\hline Samplet & 682 & 1978 \\
\hline \multicolumn{3}{|l|}{ Female child } \\
\hline Full cohort* & 38564 & 48.58 \\
\hline Samplet & 682 & 50.00 \\
\hline \multicolumn{3}{|c|}{$\begin{array}{l}\text { *Based on } 38564 \text { out of } 49321 \text { individuals included in the full conscription cohort } \\
\text { with children born before } 1994 \text {. } \\
\text { The sample included individuals in the full conscription cohort whose offspring } \\
\text { participated in the Swedish Surveys of Living Conditions. } \\
\text { ¥Upper-secondary education. }\end{array}$} \\
\hline
\end{tabular}

Among these factors, fathers' contact with police or childcare authorities, psychiatric diagnosis and smoking more than 10 cigarettes per day at conscription, and father only having uppersecondary education were the strongest predictors. These factors were associated with about a doubled risk of smoking among the offspring compared with having a father with no previous

Table 2 Characteristics of the offspring

\begin{tabular}{lcl}
\hline & $\mathbf{n}$ & Median/per cent \\
\hline Age at interview & 682 & 22 \\
Birth year & 682 & 1978 \\
Women & 341 & 50.00 \\
Smokers & 70 & 10.26 \\
Female smokers & 46 & 13.49 \\
Male smokers & 24 & 7.04 \\
\hline
\end{tabular}

Table 3 Associations between parental characteristics and offspring's smoking, in ORs with $95 \% \mathrm{Cls}$

\begin{tabular}{|c|c|c|}
\hline & $\mathrm{N}$ exposed & $\mathrm{OR}, 95 \% \mathrm{Cl}$ \\
\hline \multicolumn{3}{|l|}{ Father's characteristics } \\
\hline \multicolumn{3}{|c|}{ Contact with police or childcare authorities } \\
\hline No & 501 & 1 \\
\hline Yes & 181 & $2.36,1.41$ to 3.97 \\
\hline \multicolumn{3}{|l|}{ Psychiatric diagnosis } \\
\hline No & 622 & 1 \\
\hline Yes & 60 & $2.05,1.00$ to 4.21 \\
\hline \multicolumn{3}{|l|}{ Smoking } \\
\hline No & 302 & 1 \\
\hline $1-10$ & 182 & $1.18,0.62$ to 2.25 \\
\hline+10 & 198 & $2.01,1.11$ to 3.66 \\
\hline \multicolumn{3}{|l|}{ Risky use of alcohol } \\
\hline No & 614 & 1 \\
\hline Yes & 68 & $1.27,0.59$ to 2.73 \\
\hline \multicolumn{3}{|l|}{ Parental divorce } \\
\hline No & 619 & 1 \\
\hline Yes & 63 & $1.54,0.73$ to 3.25 \\
\hline \multicolumn{3}{|c|}{ Socioeconomic background } \\
\hline Non-manual/farmer & 219 & 1 \\
\hline Skilled worker & 164 & $0.92,0.45$ to 1.87 \\
\hline Unskilled worker & 212 & $1.92,1.08$ to 3.42 \\
\hline No class & 17 & $0.67,0.08$ to 5.37 \\
\hline \multicolumn{3}{|l|}{ Education } \\
\hline Higher & 192 & 1 \\
\hline Upper secondary & 490 & $2.02,1.03$ to 3.97 \\
\hline \multicolumn{3}{|l|}{ Mother's characteristic } \\
\hline \multicolumn{3}{|l|}{ Education } \\
\hline Higher & 200 & 1 \\
\hline Upper secondary & 482 & $1.74,0.92$ to 3.27 \\
\hline
\end{tabular}

contact with police or childcare authorities, no psychiatric diagnosis, who did not smoke, and had a higher educational level, respectively.

Table 4 shows the associations of father's IQ with offspring smoking, in basic and adjusted models. A one-step decrease on the stanine scale, corresponding to half a standard-deviation, was associated with an increased OR of 1.19 (95\% CI 1.04 to 1.53). Adjusting for father's educational level, and to a slightly lesser extent the mother's educational level, attenuated the association somewhat, while other factors had no or marginal effects on the association. In the analyses using three categories of fathers' IQ, the OR's and 95\% CI's for offspring smoking during follow-up were (with high IQ as reference): medium IQ $1.61(0.84$ to 3.09$)$ and low IQ 3.26 (1.57 to 6.78$)$ in the basic model; and medium IQ 1.39 (0.69 to 2.79) and low IQ 2.91 (1.26 to 6.72$)$ in the fully adjusted model. There was no interaction between father's IQ and sex of offspring $(p=0.89)$.

\section{DISCUSSION}

In this longitudinal study, we found that IQ of the father was strongly associated with their offspring's smoking. Several other characteristics of the fathers that were also associated with offspring smoking, such as socioeconomic background, smoking and low mental well-being in young adulthood, and educational attainment of the fathers and the mothers of the offspring, did not explain much of the association between father's IQ and offspring smoking. 
Table 4 The association between father's IQ and offspring's smoking ( $n=682)$, adjusted for father's risk factors and mother's education

\begin{tabular}{ll}
\hline & OR, $95 \%$ CI \\
\hline Basic model $^{*}$ & $1.19,1.04$ to 1.35 \\
Additional adjustment for $^{\text {Contact with police or childcare authorities }}$ & $1.17,1.02$ to 1.33 \\
Psychiatric diagnosis & $1.18,1.04$ to 1.34 \\
Smoking & $1.18,1.03$ to 1.34 \\
Risky use of alcohol & $1.18,1.04$ to 1.34 \\
Parental divorce & $1.18,1.04$ to 1.35 \\
Socioeconomic background & $1.17,1.02$ to 1.33 \\
Education & $1.14,0.99$ to 1.32 \\
Education of mother of child & $1.16,1.01$ to 1.33 \\
Full model (all variables included) & $1.14,0.98$ to 1.33 \\
\hline *Adjusted for age and year of interview. &
\end{tabular}

The analyses in this study were based on a small sample of the full cohort with follow-up smoking data. This was the result of a chance intersection of the cohort with the respondents to an entirely separate series of stratified random national surveys, namely the Swedish Surveys of Living Conditions. The relatively small sample, however, was representative of the full cohort with regard to information concerning the father. The prospective nature of the study enhanced the validity of its findings. Information on the fathers was gathered in most cases before the offspring was born and long before the establishment of lifestyle behaviours.

Smoking data among the offspring were collected between 1984 and 2009, at a time when the dangers of smoking were well publicised. It is possible, therefore, that some respondents to the follow-up surveys claimed to be non-smokers despite actually being smokers. If this was more common among the offspring of men with higher IQ, our estimates would be overestimated. Moreover, our definition of smoking during follow-up was limited by being based on only one time point and on selfreported smoking status, as a smoker or non-smoker. Thus, although we find it unlikely, there may have been a spurious association between father's IQ and offspring smoking if there was an association between father's IQ and the point in time when the offspring was sampled for the survey. We did not have information on offspring or maternal IQ. Considering that the data on parental characteristics in this study had only a marginal effect on the association between father's IQ and offspring smoking, such information would most likely be helpful in furthering understanding of the mechanisms underlying the association.

These results are in line with Hart et al's ${ }^{17}$ finding of an association between parental IQ and offspring smoking in a cohort of 179 parents and their offspring. Some recent, larger studies also found that paternal IQ was associated with other health-related outcomes in their children, such as lower risk of injuries $^{31} 32$ and fewer hours of TV watching, ${ }^{32}$ which further indicates that parents' IQ can indeed have health consequences for their offspring in various ways.

In the study by Hart et al, ${ }^{17}$ parental social class in adulthood did not explain the association between parental IQ and offspring smoking. In the present study, using data from father's childhood and adolescence, adjusting for father's childhood social class and other background variables did not affect the association with offspring smoking. By contrast, intragenerational associations between IQ and one's own smoking has been shown to attenuate ${ }^{33}$ or even be reversed ${ }^{35}$ after adjusting for various background variables.

Father's education had a small attenuating effect on the association, which might reflect the education of the father having a real effect on offspring smoking, even if this happens indirectly via, for example, social factors over and above the association between father's IQ and offspring smoking. On the other hand, the role of education in explaining the associations between IQ and various outcomes is difficult to interpret since intelligence and education are strongly correlated and affect each other. ${ }^{36}$ It has been argued that education, in some sense, is a proxy for intelligence; thus, adjusting for education in analyses of associations between intelligence and outcomes might be an overadjustment. $^{5}$

It has been suggested that mother's educational level is more important than father's education for offspring health. ${ }^{37}$ Given that IQ is strongly related to educational attainment. ${ }^{36}$ it is possible that assortative mating, the tendency to choose a mate with a similar genotype to oneself, accounts for some part of the association between father's IQ and offspring smoking. We had no information on mother's IQ, which would have been useful. However, if mother's IQ was an important factor in the association, it would have been expected that adjusting for mother's education would have had a relatively large attenuating effect on the estimate; instead, we found that it had less impact than father's education in our analyses.

It has been suggested that the association between intelligence and health is partly explained by more intelligent people being better able to make healthy choices and maintain a healthy lifestyle, ${ }^{6}$ and previous longitudinal studies have shown that IQ early in life is associated with smoking. ${ }^{3-5}$ Accordingly, it is possible that offspring's own IQ, a trait that is highly heritable, ${ }^{38}$ mediated some of the association such that offspring with higher IQ were less likely to smoke. We had no data on offspring's IQ and could not investigate this possible pathway. In previous studies of associations of parents' IQ with health behaviours, such as hours spent watching TV by their children at age around 8 years, adjusting for the child's own IQ had little or no effect on the associations. ${ }^{32}$ In the present study, however, the offspring were adolescents or adults at time of assessment of smoking and thus were more independent in their choices.

On the other hand, previous findings that the associations between IQ and smoking are largely explained by socioeconomic position $^{3-5}$ imply that it is social positioning rather than the individual's own ability to make healthy choices that accounts for the IQ-smoking association in an intragenerational perspective. In the present study, adjustment for socioeconomic and social background had little attenuating effect on the association, but we had no data on the offspring's social circumstances in adulthood.

Another possibility is that father's IQ, which is strongly associated with psychiatric disorders in adulthood in this cohort, ${ }^{21}$ is also negatively related to psychological distress in their offspring, of which smoking might be a marker. ${ }^{39}$ Even though adjusting for father's psychiatric diagnoses in early adulthood had no effect on the association, we cannot rule out the possibility that mental disorders emerged later in life and affected the psychological well-being of their offspring. Other psychosocial factors, not captured by socioeconomic position or the other variables, might also have mediated the association. The findings of a Swedish twin study suggest that shared environmental factors account for most of the association between intelligence and smoking, ${ }^{34}$ implying that the family environment might play a role. 
It has been suggested that the reason why deprived groups more often take up and persist in smoking may be linked to their generally poorer life chances and that it might be a rationale response to such circumstances. ${ }^{40}$ In accordance with the findings of other studies, ${ }^{16} 4142$ the results of this study indicate that certain life circumstances may be linked to factors measured in the previous generation even before the participants were born.

\section{CONCLUSION}

The study shows that fathers' IQ measured in early life is associated with offspring smoking. The association is independent of socioeconomic position, and of early signs of mental illness and smoking among fathers, but more knowledge is needed on the role of the mother's and the offspring's own IQ in this association. The findings suggest that IQ is a factor to consider in smoking prevention targeted at families.

\section{What is already known on this subject}

- Early-life IQ is associated with health behaviours and longevity, independent of socioeconomic background.

- Early-life IQ among parents has also been found to predict health behaviours, including smoking, in their offspring. The mechanisms are unclear.

\section{What this study adds}

- In this study of 682 randomly sampled offspring of Swedish men, lower IQ among fathers was found to be stepwise associated with a higher risk of self-reported smoking in adolescence or adulthood.

- Father's socioeconomic background and smoking, mental illness and social problems in youth did not fully account for the association.

Contributors AL, BM and TH conceived the study; AL performed the statistical analyses; ASW, AL and TH drafted the manuscript; all authors contributed important intellectual content and approved the final manuscript.

Funding This work was supported by the Swedish Council for Working Life and Social Research, grant number: 2011-0960.

Competing interests None declared.

Ethics approval The Ethics Committee at the Karolinska Institutet, Stockholm, approved the study.

Provenance and peer review Not commissioned; externally peer reviewed.

Open Access This is an Open Access article distributed in accordance with the Creative Commons Attribution Non Commercial (CC BY-NC 4.0) license, which permits others to distribute, remix, adapt, build upon this work non-commercially, and license their derivative works on different terms, provided the original work is properly cited and the use is non-commercial. See: http://creativecommons.org/ licenses/by-nc/4.0/

\section{REFERENCES}

1 Lim SS, Vos T, Flaxman AD, et al. A comparative risk assessment of burden of disease and injury attributable to 67 risk factors and risk factor clusters in 21 regions, 1990-2010: a systematic analysis for the Global Burden of Disease Study 2010. Lancet 2012;380:2224-60.
2 Chen P, Jacobson KC. Developmental trajectories of substance use from early adolescence to young adulthood: gender and racial/ethnic differences. J Adolesc Health 2012;50:154-63.

3 Batty GD, Deary IJ, Schoon I, et al. Mental ability across childhood in relation to risk factors for premature mortality in adult life: the 1970 British Cohort Study. J Epidemiol Community Health 2007:61:997-1003.

4 Taylor MD, Hart CL, Smith GD, et al. Childhood IQ and social factors on smoking behaviour, lung function and smoking-related outcomes in adulthood: Linking the Scottish Mental Survey 1932 and the Midspan studies. Brit J Health Psych 2005; 10:399-410.

5 Batty GD, Deary IJ, Macintyre S. Childhood IQ in relation to risk factors for premature mortality in middle-aged persons: the Aberdeen Children of the 1950s study. J Epidemiol Community Health 2007;61:241-7.

6 Gottfredson LS, Deary IJ. Intelligence predicts health and longevity, but why? Curr Dir Psychol Science 2004;13:1-4.

7 Calvin CM, Deary IJ, Fenton C, et al. Intelligence in youth and all-cause-mortality: systematic review with meta-analysis. Int J Epidemiol 2011;40:626-44.

8 Jefferis BJ, Power $\mathrm{C}$, Graham $\mathrm{H}$, et al. Effects of childhood socioeconomic circumstances on persistent smoking. Am J Public Health 2004;94:279-85.

9 O'Callaghan FV, O'Callaghan M, Najman JM, et al. Prediction of adolescent smoking from family and social risk factors at 5 years, and maternal smoking in pregnancy and at 5 and 14 years. Addiction 2006;101:282-90.

10 Lawlor DA, Batty GD, Morton SM, et al. Childhood socioeconomic position, educational attainment, and adult cardiovascular risk factors: the Aberdeen children of the 1950s cohort study. Am J Public Health 2005;95:1245-51.

11 Anda RF, Croft JB, Felitti VJ, et al. Adverse childhood experiences and smoking during adolescence and adulthood. JAMA 1999;282:1652-8.

12 van Loon AJM, Tijhuis M, Surtees PG, et al. Determinants of smoking status: cross-sectional data on smoking initiation and cessation. Eur J Public Health 2005;15:256-61.

13 Castrucci BC, Gerlach KK. Understanding the association between authoritative parenting and adolescent smoking. Matern Child Health J 2006;10:217-24.

14 Lacey RE, Cable N, Stafford M, et al. Childhood socio-economic position and adult smoking: are childhood psychosocial factors important? Evidence from a British birth cohort. Eur J Public Health 2011;21:725-31.

15 Sargent JD, Dalton M. Does parental disapproval of smoking prevent adolescents from becoming established smokers? Pediatrics 2001;108:1256-62.

16 Najman JM, Aird R, Bor W, et al. The generational transmission of socioeconomic inequalities in child cognitive development and emotional health. Soc Sci Med 2004;58:1147-58.

17 Hart CL, Deary IJ, Smith GD, et al. Childhood IQ of parents related to characteristics of their offspring: Linking the Scottish Mental Survey 1932 to the Midspan Family Study. J Biosoc Sci 2005;37:623-39.

18 Whitley E, Gale CR, Deary IJ, et al. Association of maternal and paternal IQ with offspring conduct, emotional, and attention problem scores. Transgenerational evidence from the 1958 British Birth Cohort Study. Arch Gen Psychiatry 2011;68:1032-8.

19 Allebeck P, Allgulander C. Psychiatric diagnoses as predictors of suicide. A comparison of diagnoses at conscription and in psychiatric-care in a cohort of 50465 young men. Br J Psychiatry 1990;157:339-44.

20 Larsson D, Hemmingsson T, Allebeck $P$, et al. Self-rated health and mortality among young men: what is the relation and how may it be explained? Scand J Public Health 2002;30:259-66.

21 Zammit S, Allebeck P, David AS, et al. A longitudinal study of premorbid IQ Score and risk of developing schizophrenia, bipolar disorder, severe depression, and other nonaffective psychoses. Arch Gen Psychiatry 2004;61:354-60.

22 David AS, Malmberg A, Brandt L, et al. IQ and risk for schizophrenia: a population-based cohort study. Psychol Med 1997;27:1311-23.

23 Hemmingsson T, Lundberg I, Diderichsen F, et al. Explanations of social class differences in alcoholism among young men. Soc Sci Med 1998;47:1399-405.

24 Sidorchuk A, Hemmingsson T, Romelsjo A, et al. Alcohol use in adolescence and risk of disability pension: a 39 year follow-up of a population-based conscription survey. PLOS ONE 2012;7:e42083.

25 Hemmingsson T, Kriebel D. Smoking at age 18-20 and suicide during 26 years of follow-up-how can the association be explained? Int J Epidemiol 2003;32:1000-4.

26 Upmark M, Hemmingsson T, Romelsjo A, et al. Predictors of disability pension among young men-The role of alcohol and psychosocial factors. Eur J Public Health 1997;7:20-8.

27 Romelsjo A, Kaplan GA, Cohen RD, et al. Protective factors and social risk-factors for hospitalization and mortality among young men. Am J Epidemiol 1992;135:649-58.

28 Allebeck P, Allgulander C, Fisher LD. Predictors of completed suicide in a cohort of 50465 young men: role of personality and deviant behavior. $\mathrm{Br}$ Med J 1988;297:176-8.

29 Hemmingsson T, Kriebel D, Tynelius $\mathrm{P}$, et al. Adolescent mental health predicts quitting smoking in adulthood: a longitudinal analysis. Eur J Public Health 2008; 18:66-70. 
30 Lundin A, Lundberg I, Allebeck P, et al. Psychiatric diagnosis in late adolescence and long-term risk of suicide and suicide attempt. Acta Psychiatr Scand 2011;124:454-61.

31 Jelenkovic $A$, Silventoinen $\mathrm{K}$, Tynelius $\mathrm{P}$, et al. Association of paternal IQ in early adulthood with offspring mortality and hospital admissions for injuries: a cohort study of 503492 Swedish children. J Epidemiol Community Health 2014;68:679-82.

32 Whitley E, Gale CR, Deary IJ, et al. Influence of maternal and paternal IQ on offspring health and health behaviours: evidence for some trans-generational associations using the 1958 British birth cohort study. Eur Psychiatry 2013;28:219-24

33 Hemmingsson T, Kriebel D, Melin B, et al. How does IQ affect onset of smoking and cessation of smoking - Linking the Swedish 1969 conscription cohort to the Swedish survey of living conditions. Psychosom Med 2008;70:805-10.

34 Wennerstad KM, Silventoinen K, Tynelius P, et al. Associations between IQ and cigarette smoking among Swedish male twins. Soc Sci Med 2010;70:575-81.

35 Johnson W, Hicks BM, McGue M, et al. How intelligence and education contribute to substance use: hints from the Minnesota Twin Family Study. Intelligence 2009;37:613-24
36 Deary IJ, Johnson W. Intelligence and education: causal perceptions drive analytic processes and therefore conclusions. Int J Epidemiol 2010;39:1362-9.

37 Lundborg P, Nilsson A, Rooth D-0. Parental education and offspring outcomes: evidence from the Swedish compulsory School Reform. Am Econ J: Appl Econ 2014;6:253-78

38 Davies $G$, Tenesa A, Payton A, et al. Genome-wide association studies establish that human intelligence is highly heritable and polygenic. Mol Psychiatry 2011;16:996-1005.

39 Kassel JD, Stroud LR, Paronis CA. Smoking, stress, and negative affect: correlation, causation, and context across stages of smoking. Psychol Bull 2003;129:270.

40 Lawlor DA, Frankel S, Shaw M, et al. Smoking and ill health: does lay epidemiology explain the failure of smoking cessation programs among deprived populations? Am J Public Health 2003;93:266-70.

41 Modin B, Vagero D, Hallqvist J, et al. The contribution of parental and grandparental childhood social disadvantage to circulatory disease diagnosis in young Swedish men. Soc Sci Med 2008;66:822-34.

42 Modin B, Fritzell J. The long arm of the family: are parental and grandparental earnings related to young men's body mass index and cognitive ability? Int J Epidemiol 2009;38:733-44. 